\title{
Multiple, discrete arcs on sunward convecting field lines in the 14-15 MLT region
}

Article

Published Version

Moen, J., Sandholt, P. E., Lockwood, M., Egeland, A. and Fukui, K. (1994) Multiple, discrete arcs on sunward convecting field lines in the 14-15 MLT region. Journal of Geophysical Research, 99 (A4). p. 6113. ISSN 0148-0227 doi: https://doi.org/10.1029/93JA03344 Available at https://centaur.reading.ac.uk/38815/

It is advisable to refer to the publisher's version if you intend to cite from the work. See Guidance on citing.

Published version at: http://dx.doi.org/10.1029/93JA03344

To link to this article DOI: http://dx.doi.org/10.1029/93JA03344

All outputs in CentAUR are protected by Intellectual Property Rights law, including copyright law. Copyright and IPR is retained by the creators or other copyright holders. Terms and conditions for use of this material are defined in the End User Agreement.

www.reading.ac.uk/centaur 
Central Archive at the University of Reading

Reading's research outputs online 


\title{
Multiple, discrete arcs on sunward convecting field lines in the 14-15 MLT region
}

\author{
J. Moen, ${ }^{1}$ P. E. Sandholt, ${ }^{1}$ M. Lockwood, ${ }^{2}$ A. Egeland, ${ }^{1}$ and K. Fukui ${ }^{3}$
}

\begin{abstract}
Ionospheric plasma flow measurements and simultaneous observations of thin $\left(-0.2^{\circ}\right.$ invariant latitude (ILAT)), multiple, longitudinally extended auroral arcs of transient nature within $74^{\circ}-76^{\circ}$ ILAT and 1030-1130 UT ( $14-15$ MLT) on January 12 , 1989, are reported. The auroral structures appeared within the luminous belt of strong 630.0-nm emissions located predominantly on sunward convecting field lines equatorward of the convection reversal boundary as identified by the European Incoherent Scatter UHF radar. The events occurred during a period of several hours quasi-steady solar wind speed $\left(\sim 700 \mathrm{~km} \mathrm{~s}^{-1}\right)$ and a radially orientated interplanetary magnetic field (IMF) with a weak northward tilt (IMF $B_{z}>0$ ). These typical dayside auroral features are related to previous studies of auroral activity related to the upward region 1 current in the postnoon sector. The discrete auroral events presented here may result from magnetosheath plasma injections into the low-latitude boundary layer (LLBL) and an associated dynamo mechanism. An alternative explanation invokes kinetic Alfvén waves, triggered either by Kelvin-Helmholtz instability at the inner (or outer) edge of the LLBL or by pressure pulse induced magnetopause surface waves.
\end{abstract}

\section{Introduction}

This paper is devoted to a category of dayside auroral activity characterized by narrow, multiple, parallel arcs striated in the east-west direction. Discrete auroral activity in the local time sector between 14 and 16 hours, where the region 1 upward field-aligned current also exhibits a maximum [Iijima and Potemra, 1978], is a common phenomenon. Lui et al. [1989] reported on bright spots frequently seen in global UV images from the Viking satellite within this time interval. Those bright spots, which did not have any systematic azimuthal motion, were, by Lui et al. [1989], related to Kelvin-Helmholtz waves driven by velocity shears at the interface region between the plasma sheet boundary layer and the low-latitude boundary layer (LLBL). A statistical study by Evans [1985], using TIROS/NOAA satellite measurements, showed that the precipitation in the 14-16 MLT sector in general appears as multiple, latitudinally thin structures ( $20 \mathrm{~km}$ average width) of energized ( $<3 \mathrm{keV}$ ) electron precipitation. Evans [1985] suggested that this category of postnoon auroral activity is likely to be associated with direct solar wind-magnetospheric interaction.

Morphological studies by, for example, Meng and Lundin [1986] indicate that the phenomenon of multiple arcs predominates in the postnoon sector and has been attributed to at least three different magnetosphere-ionosphere current coupling systems:

\footnotetext{
${ }^{\text {TDepartment }}$ of Physics, University of Oslo, Norway.

${ }^{2}$ Rutherford Appleton Laboratory, Chilton, England.

${ }^{3}$ Geophysics Directorate, Phillips Laboratory, Hanscom Air Force Base, Massachusetts.
}

Copyright 1994 by the American Geophysical Union.
1. Lundin and Evans [1985] proposed a boundary layer dynamo model explaining the formation of multiple arcs and the dawn-dusk asymmetry of occurrence. According to their closed magnetospheric model, discrete arcs are powered by solar wind filaments with excess momentum penetrating the dayside magnetospheric boundary layer by an unspecified mechanism. These gas parcels become polarized within the boundary layer, and field-aligned discharge currents, closing in the ionosphere, are set up. Discrete auroras correspond to the upward field aligned current sheet connected to that part of the intruding plasma filaments where negative space charge builds up. Lundin and Evans [1985, Figure 6] schematically illustrate that by this mechanism, multiple arcs preferentially form on the postnoon side of the cusp and to a lesser extent in the late morning sector.

The ionospheric footprint of a frontside plasma transfer event (PTE) may appear within the cleft arc with a distinct equatorward motion across the convection reversal boundary followed by a longitudinal expansion on either side of noon [Lemaire, 1977; Goertz et al., 1985; Heikkila et al., 1989]. Plasma penetration outside the subsolar region is also conceivable [Woch and Lundin, 1991]. According to statistical results by Woch and Lundin [1992], magnetosheath plasma penetration events are more strongly controlled by interplanetary magnetic field (IMF) $B_{Y}$ than $B_{Z}$, and they are embedded in regions of Sunward convecting plasma. The occurrence is positively correlated with solar wind dynamic pressure.

2. Crooker and Siscoe [1990] proposed that multiple arcs in the postnoon sector may be interpreted in terms of patchy reconnection and field line mapping distortions. They demonstrated that a round patch in the magnetopause associated with a flux transfer event (FTE) elongates as it maps along field lines into the ionosphere. The elongation increases with increasing displacement of patch location from the subsolar point. A candidate auroral signature of sporadic reconnection 
at the dayside magnetopause has been documented for IMF $\mathrm{B}_{\mathrm{Z}}<0$ conditions and described in a series of papers by Sandholt and coworkers [e.g., Sandholt et al., 1986, 1993, and references therein]. Characteristic features include an IMF $B_{Y}$ dependent east-west motion of the auroral forms along the polar cap boundary and the disappearance (fading phase) within the polar cap in the regime of mantle-type precipitation. The flux rope model of FTE signatures by Saunders et al. [1984] is consistent with an afternoon predominance of discrete arcs. The directions of the center current depends on the sign of the IMF $B_{Y}$ component. In the case of $B_{Y}<0\left(B_{Y}>0\right)$, the freshly connected flux tube is convecting toward dusk (dawn) and the center current is directed upward from (downward into) the ionosphere.

3. Torbert and Mozer [1978] suggested that electrostatic shocks [Mozer et al., 1980], commonly observed within the large-scale region 1 current distribution [Catell, 1983] are a likely source of discrete auroral arcs. Goertz [1984] showed that kinetic Alfvèn waves [Hasegawa, 1976] can explain the observations of electrostatic shocks. The kinetic Alfvèn wave may be initiated by a large-scale surface wave in the magnetospheric boundary layers when density gradients are present. The Kelvin-Helmholtz instability (KHI) in the LLBL is one of several possible candidate sources of the surface wave [cf. Wei et al., 1990].

Categories 1 and 2 above describe responses to direct impulsive solar wind plasma injections, while category 3 is a small-scale structure imbedded in the large-scale region 1 current system, excited by an MHD surface wave.

The following section includes a brief description of the instrumentation applied in this study. Then the observations are presented. In the discussion section a connection is made to previous work on magnetospheric boundary layer processes and related fine structure in the upward region 1 current. Finally, a brief summary is given.

\section{Instrumentation}

The optical instrumentation at $\mathrm{Ny}$ Ålesund, Svalbard (geographic coordinates $78.9^{\circ} \mathrm{N}, 11.9^{\circ} \mathrm{E}$; invariant latitude $76^{\circ}$ ) includes a multichannel, meridian-scanning photometer (MSP) system sensitive to the auroral green (557.7-nm) and red (630.0-nm) lines. This MSP has a $2^{\circ}$ field of view and scans roughly along the geomagnetic meridian to $10^{\circ}$ above the horizon with a scan period of 18 seconds. The optical instrumentation at $\mathrm{Ny}$ Âlesund also includes an all-sky, intensified silicon intensifier target (ISIT) TV camera system for monitoring two-dimensional dynamic behavior of discrete auroral forms. The ISIT camera has a maximum sensitivity of between 400 and 500-nm. In addition, data from an all-sky imaging photometer (ASIP) operated at 557.7-nm are also used in this study. The ASIP has a 1 -min time resolution. The ISIT and the ASIP cameras provide useful information about the auroral forms within a circular area with diameter of $\sim 1000 \mathrm{~km}$.

The auroral green (557.7-nm) and red (630.0-nm) line emissions correspond to transitions from the ${ }^{1} S$ and $D$ metastable states of oxygen (OI), respectively. Assuming that the OI 'D emission layer is near $250 \mathrm{~km}$, the MSP at 630.0$\mathrm{nm}$ surveys the latitude range from $\sim 71^{\circ}$ to $81^{\circ}$ invariant latitude (ILAT). Supplementary ion drift observation was obtained by operating the European Incoherent Scatter (EISCAT) UHF radar in the beam-swinging mode "Polar" (version SP-UK-POLI). In this experiment the beam position is alternating between two different azimuths $24^{\circ}$ apart. Postintegrated line of sight velocities are obtained at 25 equally spaced gates ranging from $71^{\circ}$ to $78^{\circ}$ ILAT for each 130-s dwell at each position. The distance between the $\mathrm{L}$ shells of adjacent gates is $\approx 35 \mathrm{~km}$, and the distance between the two beam directions varies between 220 and $660 \mathrm{~km}$. From the line of sight velocities ion flow vectors are derived every $2.5 \mathrm{~min}$ in the way described by Willis et al. [1986], by assuming that the flow is uniform between the two beam directions employed and that it varies linearly with time over each 5-min beam-swinging cycle. During transient, localized events, both of the above assumptions may be locally invalid [cf. Lockwood et al., 1990]. However, large-scale and relatively steady features, such as the convection reversal boundary near the edge of the polar cap, should be accurately reproduced by the beam-swing experiment.

The IMF was acquired by the IMP 8 spacecraft operating in the solar wind on January 12, 1989. The IMP 8 position at $1129 \mathrm{UT}$ on this day, given in geocentric solar ecliptic coordinates, was $\left(\mathrm{X}_{\mathrm{SE}}=5.8, \mathrm{Y}_{\mathrm{SE}}=-35.5, \mathrm{Z}_{\mathrm{SE}}=16.6 \mathrm{R}_{\mathrm{E}}\right)$.

\section{Observations}

The IMF data acquired by IMP 8 on January 12, 1989, is presented in Figure 1. The time resolution of these data is 15 s. Throughout the time interval from 10 to 13 UT the IMF was dominated by the $\mathrm{B}_{\mathrm{X}}$ component and was nearly constant.

The IMF $B_{Y}$ and $B_{Z}$ components were small and positive. Figure 2a shows stacked photometer traces of the $630.0-\mathrm{nm}$ and 557.7-nm auroral emissions recorded during the time interval from 1030 to 1130 UT (-14-15 MLT). Each photometer trace represents the line of sight intensity distribution along the photometer scanning direction (roughly the geomagnetic meridian). The auroral activity during this time period was characterized by multiple discrete forms (557.7$\mathrm{nm}$ ) imbedded within a quasi-stable background luminosity of $630.0-\mathrm{nm}$ emission within $\sim 74^{\circ}-77^{\circ}$ ILAT.

Figure $2 b$ shows a sequence of all-sky photographs of auroral luminosity at $557.7-\mathrm{nm}$ recorded with the ASIP. The original pictures have been digitized and transformed to geographic coordinates by assuming an emission height of $120 \mathrm{~km}$. During the transformation process, the all-sky images were limited to $\leq 80^{\circ}$ zenith because camera sensitivity falls rapidly above this zenith angle. The 557.7-nm peak intensities seen on the photometer traces correspond to narrow east-west elongated arcs. For example, the three intensity peaks seen at the 557.7-nm photometer channel near 1102 UT (cf. Figure 2a) appeared as three east-west elongated parallel arcs in the corresponding ASIP picture (cf. the left-hand image of Figure $2 \mathrm{~b}$ ). The interarc spacing was -50 $\mathrm{km}$, and the individual arc was $-10-20 \mathrm{~km}$ thick. The most prominent display during the time period from $\sim 14$ to 15 MLT was double and triple structures of longitudinally extended arcs. The transient arcs were not associated with significant east-west motion during their -2 - to 5-min lifetime. A slow poleward motion of the arcs was often observed. Individual arc structures frequently underwent highly dynamic variations. Such arc distortions appeared to be correlated with the 557.7-nm emission intensity. One such event occurred near 1104 UT (cf. Figure 2a). A sequence of digitized ISIT TV camera pictures, covering the time interval 


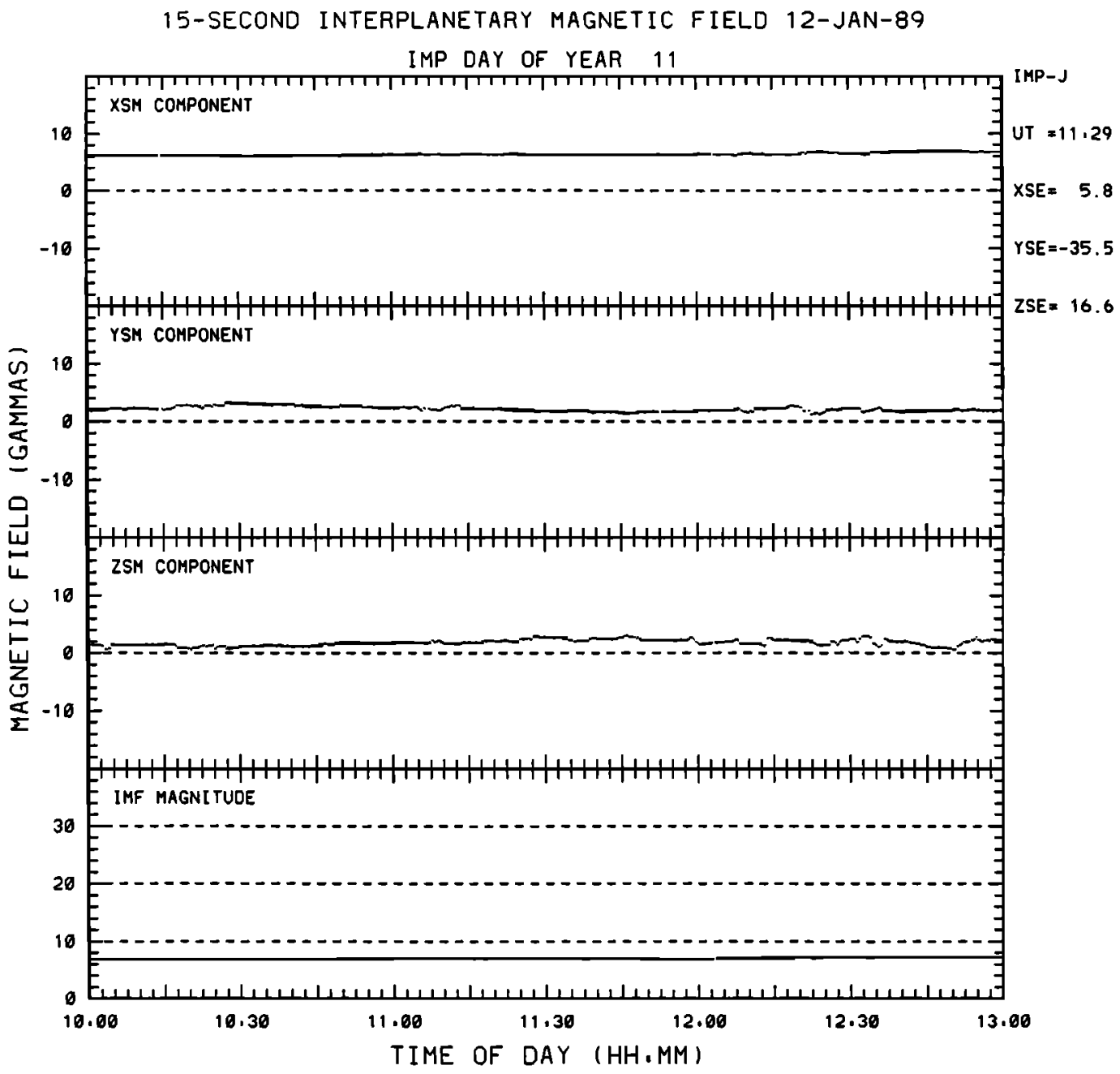

Figure 1. The 15-s IMP 8 interplanetary magnetic field data on January $12,1989 . \mathrm{X}, \mathrm{Y}$, and Z components and the field magnitude are shown from top to bottom.

from 1103:50-1105:15 UT, is presented in Figure 2c. Each of the 9 frames is a time average of about $2 \mathrm{~s}$ of video recording (starting at the time indicated). Zenith angle circles and geographic directions as well as the photometer scanning direction (in the upper left frame) are superimposed onto the frames. During the period from 1103:50 to 1104:20 UT, an east-west elongated arc wound up in an $\mathrm{S}$ form when viewed parallel to the Earths magnetic field. From 1104:30 to 1105:15 UT this auroral structure reversibly wound down again. By comparing this TV camera sequence with the photometer data (cf. Figure 2a), it is noticed that this structure wound up when the 557.7-nm intensity increased and subsequently wound down when it decreased. The strong intensity peak in the 557.7-nm photometer records ( $-30 \mathrm{kR})$ occurred when the photometer scanned through the folded structure seen at 1104:20 UT. A slow westward motion of the auroral structure associated with the spiral formation is noted in Figure 2c.

In Figure 3 EISCAT ion flow vectors are presented. The poleward and equatorward boundaries of the red line background luminosity as observed by the scanning photometer are marked by solid lines in the ion vector plot, assuming an emission altitude of $250 \mathrm{~km}$. A dashed line marks the reversal boundary between westward flow on the southward side and the eastward (anti-Sunward) flow in the northern part of the radar field of view. The three crosses at 1102 UT mark the positions of the parallel arcs observed (cf. Figures $2 \mathrm{a}$ and $2 \mathrm{~b}$ ). It is noted that the EISCAT data poleward of $\mathrm{Ny}$ Ålesund are somewhat uncertain due to the long-range characteristics of EISCAT (limited back-scattered signal and large spatial separation of the two beam directions). A striking feature is that the red background aurora as well as the discrete features were located in a latitudinal region of predominantly westward/Sunward convection.

\section{Discussion}

\section{Auroral Structure: Electron Acceleration Mechanism}

The presence of multiple discrete 557.7-nm arcs in the 1415 MLT region is taken as a manifestation of accelerated electron precipitation and associated upward field-aligned currents (FACs) out of the ionosphere. The characteristic features of the auroral display presented here, including the multiple structure of the events, the latitudinal and longitudinal dimensions, event lifetime, local time of occurrence, and location relative to the convection reversal, support the hypothesis by Torbert and Mozer [1978] and others (cf. 


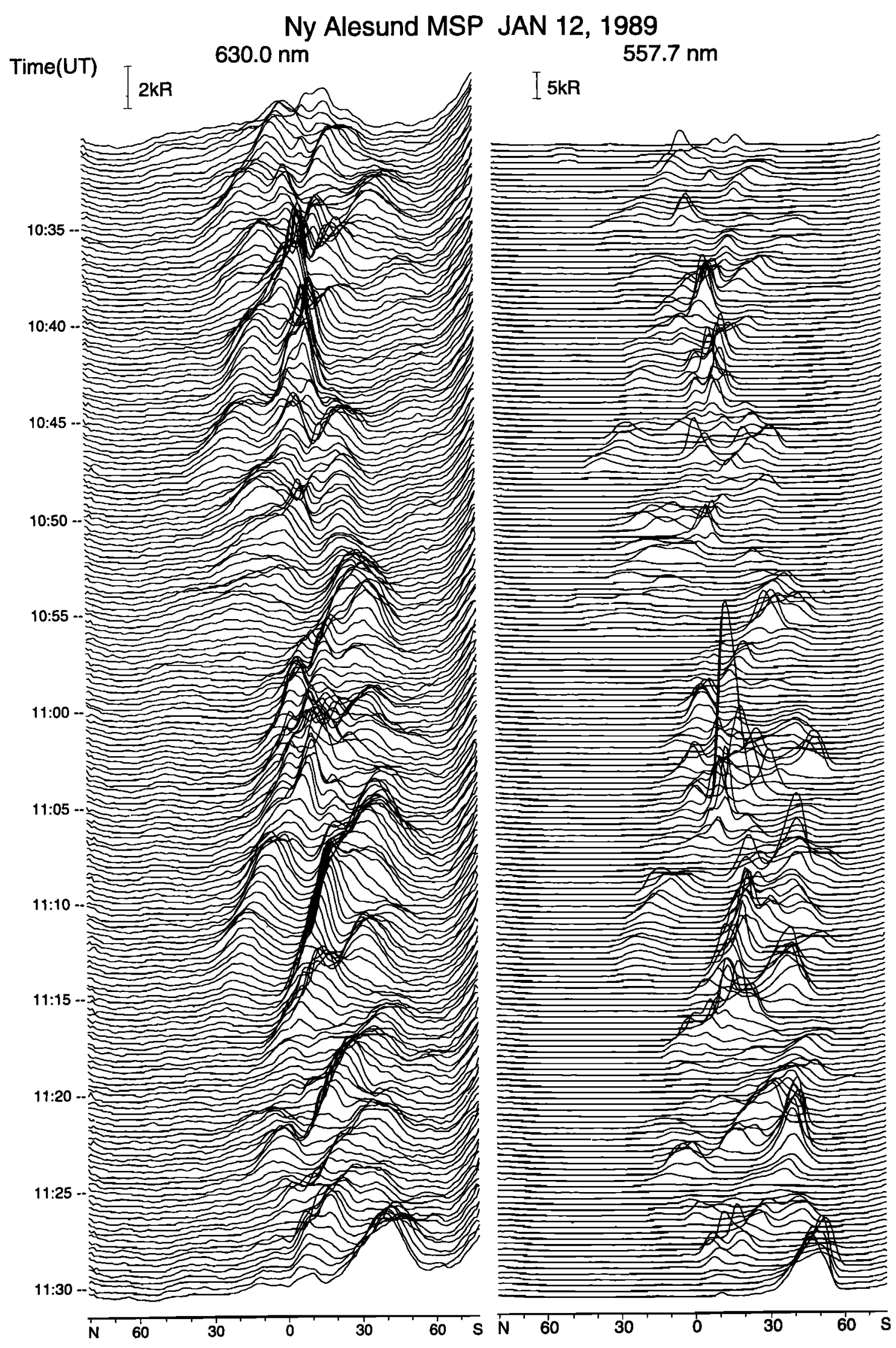

Figure 2a. North-south meridian photometer scans at wavelengths 630.0 and $557.7-\mathrm{nm}$ observed at $\mathrm{Ny}$ Ålesund (Svalbard) during a 1-hour interval (1030-1130 UT). 


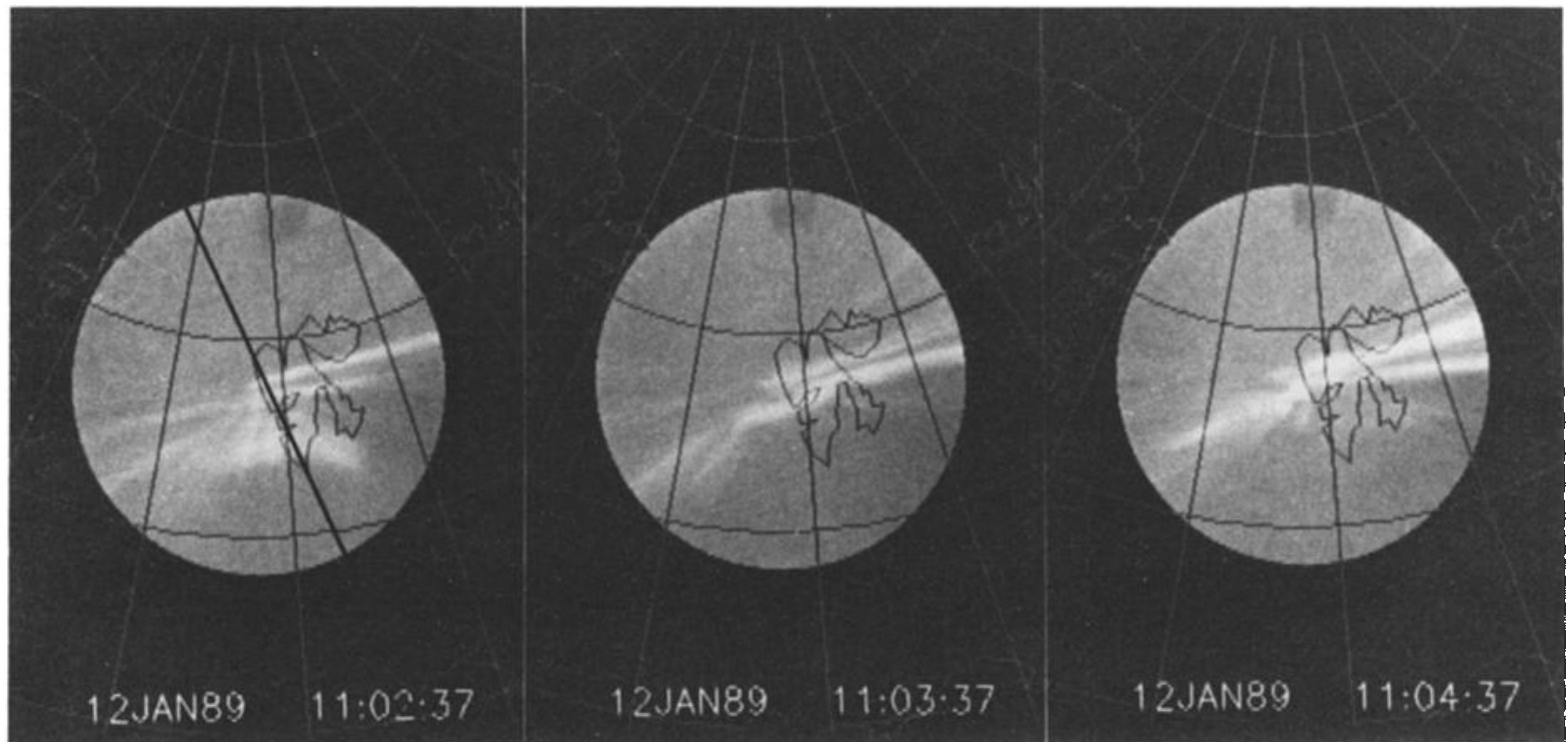

Figure 2b. All-sky photographs (Ny-Ålesund) mapped onto a geographical frame of reference for the time period 1102:37-1104:37 UT (cf. text). The camera was fitted with a 557.7-nm filter. Photometer scanning direction is marked by a solid line in the left-hand picture.

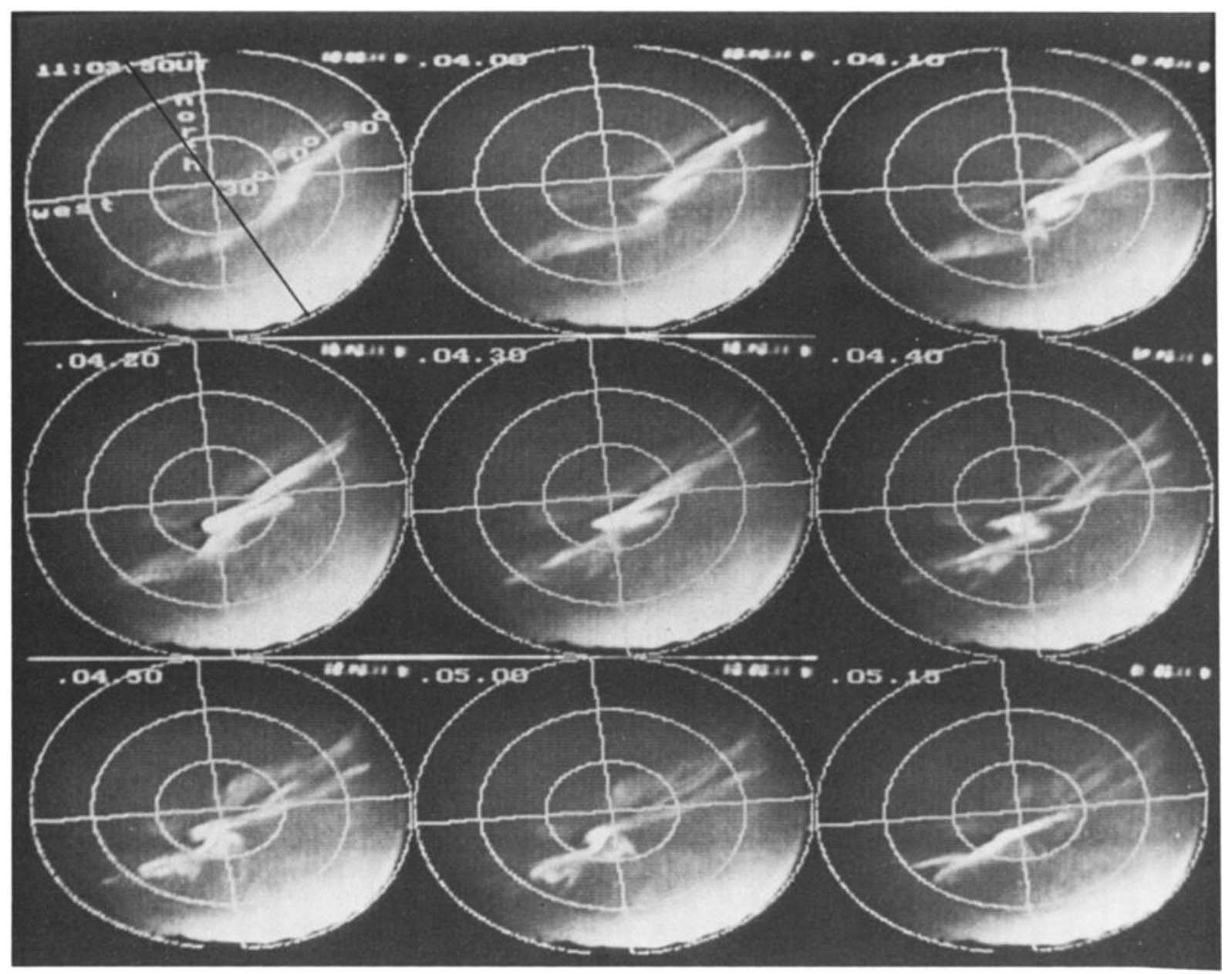

Figure 2c. Digitized intensified silicon intensifier target TV camera images from Ny Ålesund for the time interval 1103:50 to 1105:15 UT. Zenith angle circles and geographical directions are superimposed onto the pictures. In the upper left frame the photometer scanning direction is also indicated. 


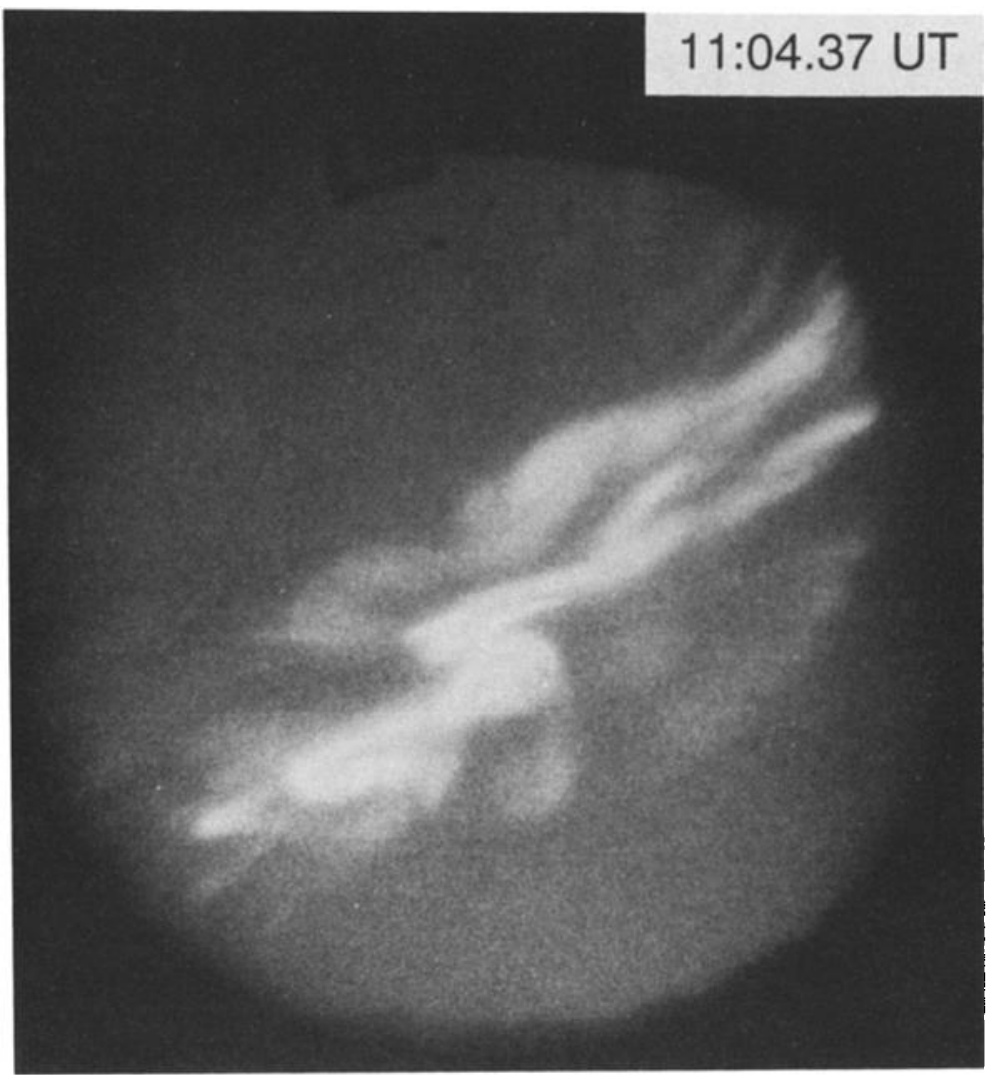

Figure 2d. All-sky photograph of 557.7-nm emissions above Ny $\AA$ lesund at 1104:37 UT. Geomagnetic North is marked by the angle at the top of the picture.

Introduction) that auroral arcs can be produced by electron acceleration in electrostatic shocks within the region 1 current system. An electrostatic shock structure is typically a latitudinally thin $\left(<0.5^{\circ} \mathrm{ILAT}\right)$ and longitudinally extended region within which a parallel DC electric field is present [Torbert and Mozer, 1978; Mozer et al., 1980; Kletzing et al., 1983]. Multiple shocks are typically imbedded within a region a few degrees wide, and their lifetime is of the order of a few minutes [Mozer et al., 1980]. The largest shocks and their occurrence frequency peaks within the large-scale region 1 current (upward) on the dusk side [e.g. Catell et al., 1979; Bennett et al., 1983]. The evening region 1 current is frequently observed to extend on the equatorward side of the convection boundary [Catell et al., 1979; Mozer et al., 1980].

The observations of electrostatic shocks/discrete arcs may be explained by the properties of the kinetic Alfvèn wave which generates parallel electric fields [e.g., Hasegawa, 1976; Lysak and Carlson, 1981; Lysak and Dum, 1983; Goertz, 1984]. The kinetic Alfvèn wave can propagate across the magnetic field and may hence explain the phenomenon of multiple arc formation [Goertz, 1984]. The kinetic Alfvèn wave is always accompanied by the MHD surface wave by which it is driven. A KHI might be a good candidate for triggering kinetic Alfvèn waves.

\section{Magnetospheric Plasma Source(s) and Field Topologies}

Based on plasma source information (electron energy and number density) inferred from TIROS/NOAA electron energy spectra, Evans [1985] suggested that the 14-16 MLT discrete auroral activity is likely driven by direct solar wind-magnetosphere interactions rather than being an extension of the nightside auroral activity.

During the time period considered in this study, IMF was northward tilted (IMF $B_{z}>0$ ) and dominated by its radial component (see Figure 1). This is taken to be an unfavourable condition for merging in the subsolar magnetopause region. Magnetic merging on the high-latitude magnetopause can occur during such circumstances [Maezawa, 1976]. According to the standard model of merging, the initial motion of newly opened field lines is controlled by magnetic tension. When both IMF $B_{Y}$ and $B_{Z}$ are positive, bursty merging between the IMF and high-latitude boundary layer field lines is expected to appear in the postnoon ionosphere as an auroral brightening poleward of the preexisting cusp/cleft arc [Basinska et al., 1992]. The auroral structure subsequently propagates in the west and equatorward directions [cf. Sandholt, 1991]. With regard to temporal and spatial evolution, the active auroral forms under consideration here appear to be different from the expected FTE footprint signatures. The IMF $B_{Y}$ amplitude of $-4 \mathrm{nT}$ could not account for a local time shift of the ionospheric cusp region into the 14-15 MLT region. Moreover, during an extended period of northward directed IMF, it seems unreasonable to observe open flux with auroral activity at $\sim 74.5^{\circ}$ ILAT (cf. Figure 3, in which latitudinal positions of the three arcs observed at 1102 UT are marked by crosses). Thus this active aurora is unlikely to be connected with magnetic merging. It is suggested that this aurora was located on closed magnetic field lines. 


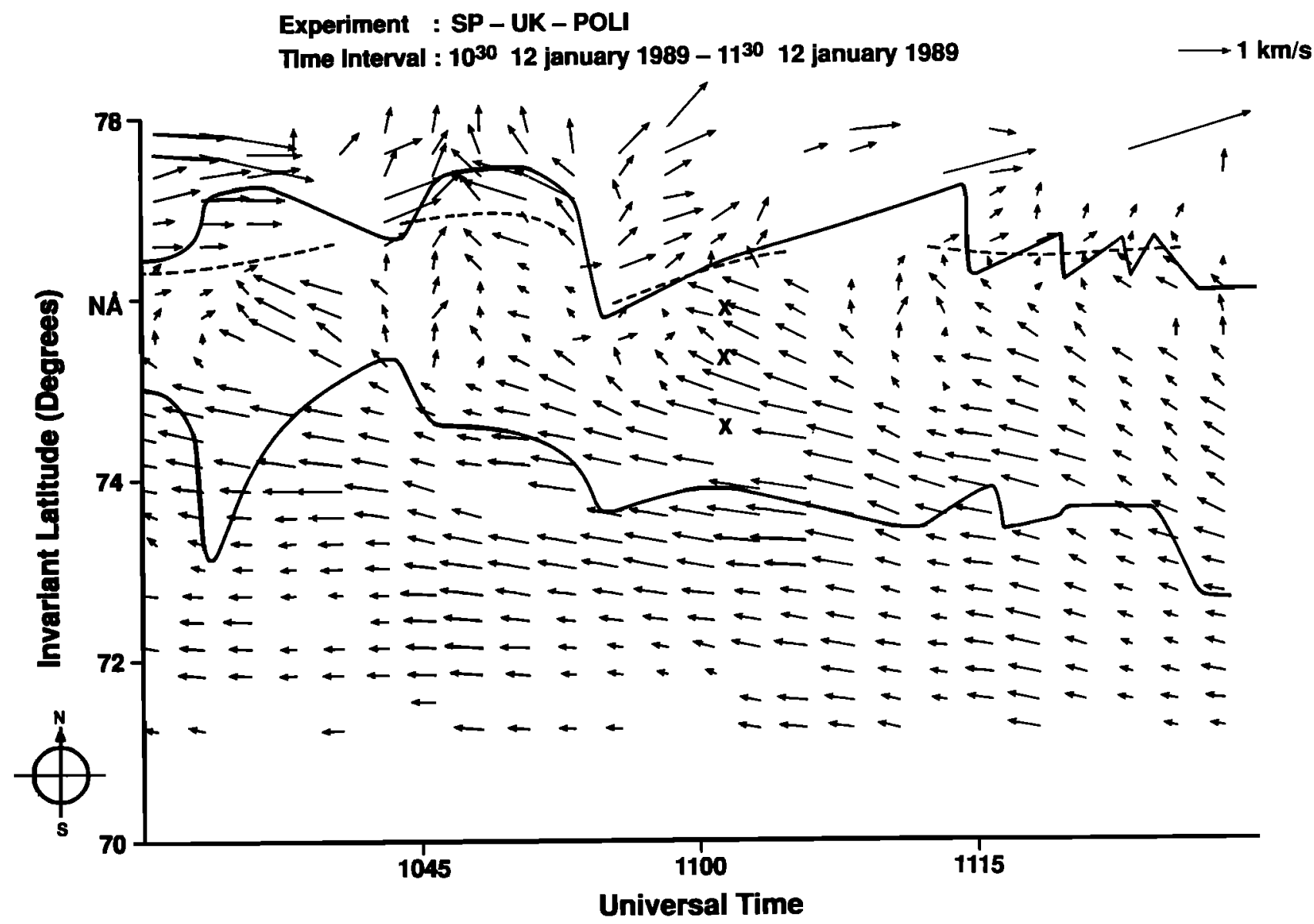

Figure 3. Ion drift vectors at 25 range gates within $71^{\circ}-78^{\circ}$ invariant latitude and their relationship with auroral observations. The dashed line marks the convection reversal boundary, and the solid lines mark the poleward and equatorward boundaries of $630.0-\mathrm{nm}$ emission observed by the meridian-scanning photometer. The three crosses at 1102 UT indicate the latitudinal positions of the parallel arcs observed (cf. Figures $2 \mathrm{a}$ and $2 b$ ).

The magnetospheric source region(s) of dayside auroras are not easily identified from optical data alone. In the present case it is seen (Figure 3) that the red line luminous arc, within which the discrete arc structures were embedded, was located mostly on Sunward convection. The red arc was only occasionally spanning the flow reversal boundary. According to the convection model of Siscoe et al. [1991], the ion flow reversal lies within the LLBL slightly equatorward of the polar cap boundary. Based on the combined optical and ion drift data, it is suggested that the discrete postnoon ( 14-15 MLT) auroral activity reported here took place on field lines mapping to the boundary plasma sheet or to the vicinity of the low-latitude boundary layer/plasma sheet boundary [cf. Vasyliunas, 1979; Newell et al., 1991; Newell and Meng, 1992].

\section{Upstream Conditions and Plasma Penetration Events}

During periods of radially oriented IMF, strong pressure and field variability can be produced at the bow shock and subsequently propagate toward the magnetopause [Fairfield et al., 1990]. Magnetosheath plasma irregularities increase the probability for impulsive entry of magnetosheath plasma clouds through the magnetopause. According to Lemaire et al. [1979], plasma injections into the magnetopause are possible when the plasma filament has an excess momentum density with respect to the background plasma and, furthermore, an antiparallel field orientation is favorable for plasma penetration. Obliquely oriented fields give rise to forces repelling the solar wind plasma irregularities from the magnetopause surface. Results by Woch and Lundin [1992] indicate that during a period of radially oriented IMF with a positive IMF $B_{Y}$ component, as in this case (cf. Figure 1), a preference for impulsive magnetosheath plasma transfer across the dusk flank of the magnetosphere is expected. Their observations indicated that the occurrence probability of plasma penetration events also increases with increasing solar wind dynamic pressure. During the actual time period, the solar wind speed was $-700 \mathrm{~km} \mathrm{~s}^{-1}$ which implies a fairly high solar wind dynamic pressure. Plasma penetration events were identified by Woch and Lundin [1992] within the region populated by ring current/plasma sheet particles, deep inside the region of Sunward convection.

Let us assume that the occurrence of multiple east-west elongated arcs is related to several plasma penetration events. According to the boundary layer dynamo model for filamentary plasma injections [cf. Lundin and Evans, 1985], a discrete arc is related to the edge of the PTE footprint associated with Birkeland currents out of the ionosphere. If each of the east-west aligned discrete arcs actually displays 
one edge of a PTE footprint, the direction of the event expansion is along the arc orientation, that is eastward in the ppstnoon sector. Observations by Woch and Lundin [1992] indicated that the plasma filaments intrude into the magnetosphere with the magnetosheath flow velocity, corresponding to 3-8 $\mathrm{km} \mathrm{s}^{-1}$ in the ionosphere. However, in the all-sky imaging the east-west extended discrete arcs appeared to be switched on and off, without showing any clear east-west expansion. If the plasma penetration events expand tailward, why did they not correspond to eastward expanding auroral forms in the postnoon ionosphere? The answer may be that they propagate into the local time region covered by the allsky camera field of view without producing any discrete auroral display. In the winter time polar ionosphere, in the absence of energetic particle precipitation, the $E$ region electron density is low (no significant photoionization), and hence also the Pedersen conductance (height integrated Pedersen conductivity) is low. The lifetime of the injection events is inversely proportional to the Pedersen conductance [e.g., Lemaire, 1977; Lundin, 1984]. A low ionospheric conductivity (dissipation rate) means a long event lifetime, and hence a plasma injection filament may penetrate deep into the magnetosphere. Discrete auroral activity is postponed until the onset of a field-aligned potential drop. The beam of electrons being accelerated through this potential drop provides enhanced ionization and a corresponding increase in the Pedersen conductance (maybe up to a factor of 10) and dissipation rate. This leads to an effective breaking of the intruding plasma filament. Thus a discrete arc structure may be a resulting signature of the breaking phase of the plasma penetration event. According to this explanation, the lifetime of the transient form corresponds to the duration of the breaking phase of the plasma penetration. In one case, Lundin [1984] estimated the event decay time to be $290 \mathrm{~s}$ (assuming a Pedersen conductance of $1 \mathrm{mho}$ ), which actually is of the same order as the observed lifetime $(2-5 \mathrm{~min})$ of discrete arcs.

When PTEs occur on Sunward convecting field lines; the polarization and convection electric field are oppositely directed, which will introduce a net reduction of Sunward convection. The time and spatial resolution of the EISCAT beam-swing experiment (SP-UK-POLI) were insufficient to reveal transient ion flow changes. The expected lifetime of the events within the EISCAT radar field of view is less or comparable to one beam swing cycle period ( $5 \mathrm{~min}$ ).

\section{Kelvin-Helmholtz Instabilities and Magnetopause Pressure Waves}

Lee et al. [1981] have shown that the velocity shear regions at the inner edge of the magnetospheric boundary layer are almost always unstable to KHI, whereas the instability at the outer edge of the boundary layer depends on the magnitude and direction of the magnetosheath magnetic field and the magnetosheath plasma flow. For high solar wind speed, as in this case, the probability of exciting KHI at the outer edge of LLBL is increased. During a period with a radially oriented magnetic field (as in the present case), the probability for the magnetopause mode of $\mathrm{KHI}$ is expected to increase toward dawn and dusk where the magnetospheric field is increasingly stretched tailward. The velocity threshold needed for a $\mathrm{KHI}$ to develop decreases with decreasing angle between the magnetospheric and magnetosheath magnetic fields [e.g. Lee et al., 1981].
Lui et al. [1989] suggested that the occurrence of dayside auroral bright spots (spatially periodic) is associated with small-scale upward FACs which in turn are related to $\mathrm{KHI}$ at the inner edge of the LLBL. These bright spot observations, which have no systematic east-west motion, may be related to the auroral activity reported here. In a recent numerical study Wei and Lee [1993] showed that KHI may develop within the LLBL because of a driven plasma flow along the magnetopause. According to their simulations, a boundary layer Kelvin-Helmholtz wave produces plasma vortices which (when viewed from above the equatorial plane) rotate counterclockwise (clockwise) in the postnoon (prenoon) sector [Wei and Lee, 1993]. The clockwise and counterclockwise vortices are associated with positive and negative space charges, respectively. These magnetospheric flow vortices are coupled to the conducting ionosphere (via Alfvèn waves and the associated FACs), where a similar set of vortices is created. Wei and Lee [1993] related the postnoon LLBL vortices, and their ionospheric signatures, to the Viking observations of auroral bright spots. According to their model results, the formation of plasma vortices within the LLBL is located outward from the main convection reversal. The corresponding ionospheric signatures should then be located poleward of the convection reversal.

Vortex-like flow structures and associated ionospheric Hall currents give rise to a specific category of ground magnetic field oscillations in the Pc 5 regime [cf. Friis-Christensen et al., 1988; Glassmeier, 1992]. An isolated traveling twin vortex structure and associated impulsive ground magnetic pulsation event may be produced in response to a sudden solar wind dynamic pressure variation. A series of traveling twin vortices was related to KHI at the inner edge of the LLBL by McHenry et al. [1990a, b]. The discrete auroral activity studied here was not accompanied by an extended sequence of sinusoidal magnetic field perturbations on Svalbard. However, as pointed out by McHenry et al. [1990a], Pc 5 waves occur predominantly in the prenoon sector. The nature of afternoon pulsations appears to be more irregular. This prepostnoon asymmetry in vorticity may be an effect of field-aligned potential drop associated with upward FACs and discrete auroral display in the afternoon sector.

Ny Ålesund, Jan. 12, 1989

Magnetic pulsations, $\mathrm{H}$ and $\mathrm{D}$ components

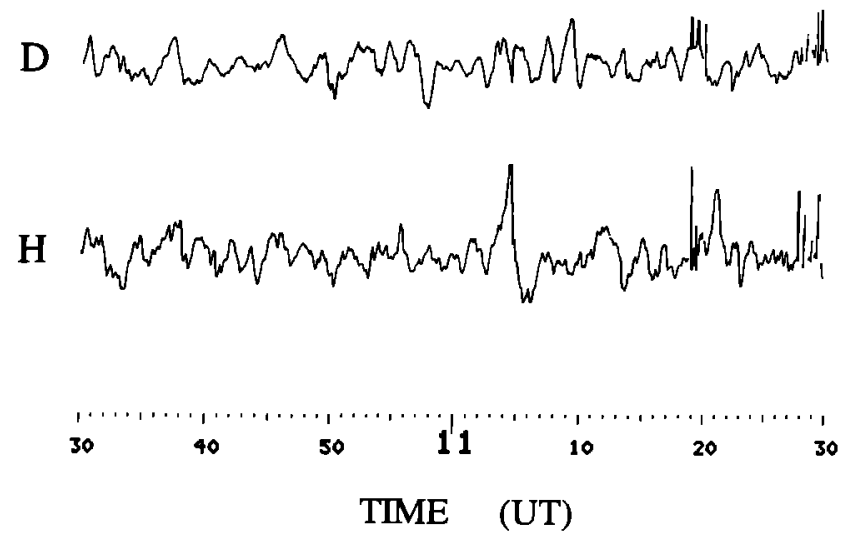

Figure 4. $\mathrm{H}$ and $\mathrm{D}$ components magnetic pulsation activity recorded in Ny Ålesund during 1030-1130 UT on January 12, 1989. 
Localized energetic particle precipitation produces inhomogenities in the conducting ionosphere. Figure 4 shows the $\mathrm{H}$ and D components pulsation recordings in Ny Ålesund for the 1-hour interval from 1030 to 1130 UT. A pronounced magnetic impulse event was observed between 1103 and 1108 UT with a positive-negative bipolar $\mathrm{H}$ component deflection accompanied by a positive $\mathrm{D}$ component excursion. This impulsive magnetic field signature bears resemblance to that expected of an isolated traveling twin vortex system, possibly because of a solar wind pressure pulse impinging the magnetopause [e.g., Glassmeier, 1992]. This impulsive magnetic field signature coincides with the multiple arcs presented in Figures $2 b$ and $2 c$. It should be emphasized that the EISCAT UHF radar operated in the SPUK-POLI experiment mode could not resolve such flow vortices even though they might exist. The lifetime of auroral and magnetic events was of the same order as the beam swing period, and the distance between the beam directions was probably too large.

The transient brightening events reported here were located on Sunward convecting field lines equatorward of the polar cap convection reversal (see Figure 3). Thus these arcs were presumably not located on field lines which mapped directly to the excitation regions of KHIs or magnetopause pressure waves. This observation, however, does not imply that the auroral activity could not be related to such boundary layer mechanisms. Recent simulations by Miura [1992] showed that a Kelvin-Helmholtz instable velocity shear layer at the magnetopause may generate vortices which diffuse Earthward during their evolution. Magnetopause surface waves may mode-couple to kinetic Alfvèn waves in the magnetospheric boundary layers when density gradients are present [Hasegawa, 1976]. As was pointed out in the first subsection above, the kinetic Alfvèn wave my explain the generation of a field-aligned potential drop and hence the formation of multiple arcs.

\section{Rotational Auroral Structures}

Now let us consider the rotational distortion observed by the all-sky TV imagery between 1104 and 1105 UT (see Figure 2c). Auroral vortices have been studied in detail by Hallinan and Davis [1970]. They divided rotational structures into three major categories: spirals, curls, and folds. According to their classification, curls and folds are small- and intermediate-scale phenomena with scale lengths of $-5 \mathrm{~km}$ and $-20 \mathrm{~km}$, respectively, while spirals cover a larger scale $(>50 \mathrm{~km})$. The curls are rotating clockwise when viewed parallel to the magnetic field, in a manner consistent with $\mathbf{E}$ $\mathbf{X} \mathbf{B}$ drift surrounding a field-aligned sheet of excess negative charge. Folds and spirals, on the other hand, exhibit counterclockwise rotation (as seen parallel to B) and are interpreted as resulting from magnetic shear due to a sheet of upward FACs [Hallinan, 1976]. Additionally, both spirals and folds are reversible, while curls are not. The particular auroral form under consideration here wound up in a counterclockwise rotational sense and thereafter reversibly unwound in a way consistent with fold/spiral formation. As the 557.7-nm intensity increased to about $30 \mathrm{kR}$, the spiral correspondingly wound up, and as the 557.7-nm intensity decreased, the spiral subsequently wound down again. By taking increased (decreased) green line emission intensity as an indicator of increasing (decreasing) upward current density [cf. Lanchester and Rees, 1987], our observation is attribu- table to the theory of spirals/folds [Hallinan, 1976]. Figure $2 \mathrm{~d}$ shows an all-sky photograph of 557.7-nm emission taken at 1104:37 UT, from which we infer the wavelength $(\lambda)$ of the distorted auroral arc. Assuming an emission altitude of $120 \mathrm{~km}$, the spatial scale length is estimated to be $-100 \mathrm{~km}$. Thus, according to Hallinan [1976], we are dealing with a spiral formation.

The auroral spiral structure due to magnetic field shear must be associated with a vortical plasma motion [cf. Southwood and Kivelson, 1991]. On smaller scales than the resistive scale length for magnetosphere-ionosphere coupling $(\sim 100 \mathrm{~km})$ the relationship between ionospheric and magnetospheric vortices is complicated by the existence of fieldaligned potential drops and the resulting decoupling between the magnetosphere and the ionosphere [cf. Weimer et al., 1985].

\section{Summary}

Multiple east-west elongated arcs in the postnoon sector ( 14-15 MLT) have been studied by combining simultaneous optical and EISCAT ion drift observations. Occurrence of thin $(-20 \mathrm{~km})$, multiple arcs were observed on Sunward convection, that is on the equatorward side of the flow reversal boundary. The discrete auroral forms embedded within the luminous background arc were not propagating/expanding in the east-west direction during their life-time of 2-5 min. These arcs and bands are suggested to be a manifestation of fine structure within the large-scale region 1 current and may represent a closer view on the auroral bright spots observed from Viking [Lui et al., 1989] and/or fan-shaped arcs observed by DMSP imagery [Meng and Lundin, 1986]. Evidence of auroral spiral formation consistent with a sheet of intense upward FAC and associated magnetic field shear/plasma vorticity has been demonstrated.

Basically, two different mechanisms of discrete arc formation were suggested. The auroral activity could represent the braking phase of magnetosheath plasma injection events. Alternatively, large-scale MHD surface waves (e.g., Kelvin-Helmholtz waves) may mode convert into a kinetic Alfvén wave which can explain the formation of multiple discrete arcs [Hasegawa, 1976]. The spatial structure of the auroral activity resembles satellite observations of electrostatic shocks [e.g., Torbert and Mozer, 1978]. Thus the auroral activity may indirectly be related to Kelvin-Helmholtz instabilities operating at the inner (or outer) edge of the LLBL, or to perturbations of the magnetopause pressure balance. The presently available data may not allow us to discriminate between these mechanisms.

Acknowledgments. The IMP 8 magnetic field data was kindly provided by R. Lepping, Goddard Space Flight Center, Greenbelt, Maryland. Thanks are also due to T. Oguti, Research Institute of Atmospherics, Nagoya University for auroral images taken by his ISIT camera in Ny Ålesund. It is a great pleasure to thank the EISCAT staff for their valuable collaboration. EISCAT is being jointly funded by the Science and Engineering Research Council (U.K.), Centre National de la Recherche Scientifique (France), Max-Plank Gesellschaft (Germany), Suomen Akatemia (Finland), Norges Allmennvitenskapelige Forskningsråd (Norway), and Naturvetenskapeliga Forskningsrådet (Sweden). This work has been supported by grants from Norges Allmennvitenskapelige Forskningsråd and British Council under the program "NAVF/British Council joint 
research projects 1991." The optical observation campaign in Ny Ålesund benefited from economical (grant NP 4/91) and technical support from the Norwegian Polar Research Institute.

The Editor thanks P. T. Newell and R. Lundin for their assistance in evaluating this paper.

\section{References}

Basinska, E. M., W. J. Burke, N. C. Maynard, W. J. Hughes, J. D. Winningham, and W. B. Hanson, Small-scale electrodynamics of the cusp with northward interplanetary magnetic field, J. Geophys. Res., 97, 6369-6379, 1992.

Bennett, E. L., M. Temerin, and F. S. Mozer, The distribution of auroral electrostatic shocks below $8000 \mathrm{~km}$ altitude, $J$. Geophys. Res., 88, 7107-7120, 1983.

Catell, C., Association of field-aligned currents with small-scale auroral phenomena, in Magnetospheric Currents, Geophys. Monogr., Ser. vol. 28, edited by T. A. Potemra, pp. 304-314, AGU, Washington, D.C., 1983.

Catell, C., R. Lysak, R. B. Torbert, and F. S. Mozer, Observations of differences between regions of current flowing into and out of the ionosphere, Geophys. Res. Lett., 6, 621-624, 1979.

Crooker, N. U., and G. L. Siscoe, On mapping flux transfer events to the ionosphere, J. Geophys. Res., 95, 3795-3799, 1990.

Evans, D. S., The characteristics of a persistent auroral arc at the high latitude in the 1400 MLT sector, in The Polar Cusp, edited by J. Holtet and A. Egeland, pp. 99-109, D. Reidel, Norwell, Mass., 1985.

Fairfield, D. H., W. Baumjohann, G. Paschmann, H. Lühr, and D. G. Sibeck, Upstream pressure variations associated with the bow shock and their effects on the magnetosphere, $J$. Geophys. Res., 95, 3773-3786, 1990.

Friis-Christensen, E., M. A. McHenry, C. R. Clauer, and S. Vennestrøm, Ionospheric travelling convection vortices observed near the polar cleft: A triggered response to sudden changes in the solar wind, Geophys. Res. Lett., 15, 253-256, 1988.

Glassmeier, K.-H., Travelling magnetospheric convection twin-vortices: Observation and theory, Ann. Geophys., 10, 547-565, 1992.

Goertz, C. K., Kinetic Alfvèn waves on auroral field lines, Planet. Space. Sci., 11, 1387-1392, 1984.

Goertz, C. K., E. Nilsen, A. Korth, K. H. Glassmeier, C. Haldoupis, P. Hoeg, and D. Hayward, Observations of possible ground signatures of flux transfer events, J. Geophys. Res., 90, 4069-4078, 1985.

Hallinan, T. J., Auroral spirals, 2, Theory, J. Geophys. Res., 81, 3959-3965, 1976.

Hallinan, T. J., and T. N. Davis, Small scale auroral arc distortions, Planet. Space Sci., 18, 1735-1744, 1970.

Hasegawa, A., Particle acceleration by MHD surface wave and formation of aurora, J. Geophys. Res., 81, 5083-5090, 1976.

Heikkila, W. J., T. Stockflet Jörgensen, L. J. Lanzerotti, and C. G. Maclennon, A transient auroral event on the dayside, $J$. Geophys. Res., 94, 15,291-15,305, 1989.

Iijima, T., and T. A. Potemra, Large-scale characteristics of field-aligned currents associated with substorms, J. Geophys. Res., 83, 599-615, 1978.

Kletzing, C., C. Catell, F. S. Mozer, S.-I. Akasofu, and K. Makita, Evidence for electrostatic shocks as the source of discrete auroral arcs, J. Geophys. Res., 88, 4105-4113, 1983.

Lanchester, B. S., and M. H. Rees, Field-aligned current reversal and fine structure in a dayside auroral arc, Planet. Space Sci., 35, 759-768, 1987.

Lee, L. C., R. K. Albano, and J. R. Kan, Kelvin-Helmholtz instability in the magnetopause-boundary layer region, $J$. Geophys. Res., 86, 54-58, 1981.
Lemaire, J., Impulsive penetration of filamentary plasma elements into the magnetospheres of the Earth and Jupiter, Planet. Space Sci., 25, 887-890, 1977.

Lemaire, J., M. J. Rycroft, and M. Roth, Control of impulsive penetration of solar wind irregularities into the magnetosphere by the interplanetary magnetic field direction, Planet. Space Sci., 27, 47-57, 1979.

Lockwood, M., P. E. Sandholt, A. D. Farmer, S. W. H. Cowley, B. Lybekk, and V. N. Davda, Auroral and plasma flow transients at magnetic noon, Panet. Space Sci., 38, 973-993, 1990.

Lui, A. T. Y., D. Ventkatesan, and J. S. Murphree, Auroral bright spots on the dayside oval, J. Geophys. Res., 94, 55155522, 1989.

Lundin, R., Solar wind energy transfer regions inside the dayside magnetopause, II, Evidence for an MHD generator process, Planet. Space Sci., 32, 757-770, 1984.

Lundin, R., and D. S. Evans, Boundary layer plasmas as a source for high-latitude, early afternoon, auroral arcs, Planet. Space Sci., 33, 1389-1406, 1985.

Lysak, R. L., and C. W. Carlson, The effect of microscopic turbulence on magnetosphere-ionosphere coupling, Geophys. Res. Lett., 8, 269-272, 1981.

Lysak, R. L., and C. T. Dum, Dynamics of magnetosphereionosphere coupling including turbulent transport, J. Geophys. Res., 88, 365-380, 1983.

Maezawa, K., Magnetospheric convection induced by the positive and negative $Z$ components of the interplanetary magnetic field: Quantitative analysis using polar cap magnetic records, J. Geophys. Res., 81, 2289-2303, 1976.

McHenry, M. A., C. R. Clauer, E. Friis-Christensen, P. T. Newell, and J. D. Kelly, Ground observations of magnetospheric boundary layer phenomena, J. Geophys. Res., 95, 14,995-15,005, 1990a.

McHenry, M. A., C. R. Clauer, and E. Friis-Christensen, Relationship of solar wind parameters to continuous, dayside, high latitude travelling ionospheric vortices, J. Geophys. Res., 95, 15,007-15,022, $1990 \mathrm{~b}$.

Meng, C.-I., and R. Lundin, Auroral morphology of the midday oval, J. Geophys. Res., 91, 1572-1584, 1986.

Miura, A., Kelvin-Helmholtz instability at the magnetospheric boundary: Dependence on the magnetosheath sonic Mach number, J. Geophys. Res., 97, 10,655-10,675, 1992.

Mozer, F. S., C. A. Cattell, M. K. Hudson, R. L. Lysak, M. Temerin, and R. B. Torbert, Satellite measurements and theories of low altitude auroral particle acceleration, Space Sci. Rev., 27, 155-213, 1980.

Newell, P. T., and C.-I. Meng, Mapping the dayside ionosphere to the magnetosphere according to particle precipitation characteristics, Geophys. Res. Lett., 19, 609-612, 1992.

Newell, P. T., W. J. Burke, E. R. Sanchez, C.-I. Meng, M. E. Greenspan, and C. R. Clauer, The low-latitude boundary layer and the boundary plasma sheet at low altitude: Dayside precipitation regions and convection reversal boundaries, $J$. Geophys. Res., 96, 21,013-21,023, 1991.

Sandholt, P. E., Auroral electrodynamics at the cusp/cleft poleward boundary during northward interplanetary magnetic field, Geophys. Res. Lett., 4, 805-808, 1991.

Sandholt, P. E., C. S. Deehr, A. Egeland, B. Lybekk, R. Viereck, and G. J. Romick, Signatures in the dayside aurora of plasma transfer from the magnetosheath, J. Geophys. Res., 91, 10,063-10,079, 1986.

Sandholt, P. E., J. Moen, A. Rudland, D. Opsvik, W. F. Denig, and T. Hansen, Auroral event sequences at the dayside polar cap boundary for positive and negative IMF $\mathrm{B}_{\mathrm{Y}}, J$. Geophys. Res., 98, 7737-7755, 1993.

Saunders, M. A., C. T. Russell, and N. Sckopke, Flux transfer events: Scale size and interior structure, Geophys. Res. Lett., 11, 131-134, 1984.

Siscoe, G. L., W. Lotko, and B. U. Ö. Sonnerup, A high- 
latitude, low-latitude boundary layer model of the convection current system, J. Geophys. Res., 96, 3487-3495, 1991.

Southwood, D. J., and M. Kivelson, An approximate description of field-aligned currents in planetary magnetic field, $J$. Geophys. Res., 96, 67-75, 1991.

Torbert, R. B., and F. S. Mozer, Electrostatic shocks as the source of discrete arcs, Geophys. Res. Lett., 5, 135-138, 1978.

Vasyliunas, V. M., Interaction between the magnetospheric boundary layers and the ionosphere, in Magnetospheric Boundary Layers, edited by Bruce Battrick, Eur. Space. Agency Spec. Publ., ESA SP-148, 387, 1979.

Wei, C. Q., and L. C. Lee, Coupling of magnetopause boundary layer to the polar ionosphere, J. Geophys. Res., 98, 5707$5725,1993$.

Wei, C. Q., L. C. Lee, and A. L. La Belle-Hamer, A simulation study of vortex structure in the low-latitude boundary layer, J. Geophys. Res., 95, 20,793-20,807, 1990.

Weimer, D. R., C. K. Goertz, D. A. Gurnett, N. C. Maynard, and J. L. Burch, Auroral zone electric fields from DE 1 and 2 at magnetic conjunctions, J. Geophys. Res., 90, 7479-7494, 1985.

Willis, D. M., S. W. H. Cowley, A. P. van Eyken, B. J. I.
Bromage, H. Rishbeth, P. R. Smith, and S. R. Crothers, A survey of simultaneous observations of high-latitude ionosphere and interplanetary field with EISCAT and AMPTEUKS, J. Atmos. Terr. Phys., 48, 987-1008, 1986.

Woch, J., and R. Lundin, Temporal magnetosheath plasma injection observed with Viking: A case study, Ann. Geophys., 9, 133-142, 1991.

Woch, J., and R. Lundin, Signatures of transient boundary layer processes observed with Viking, J. Geophys. Res., 97, 14311447, 1992.

A. Egeland, J. Moen, and P. E. Sandholt, Department of Physics, University of Oslo, P.O. Box 1048 Blindern, N-0316 Oslo, Norway.

K. Fukui, Phillips Laboratory, Geophysics Directorate, Ionospheric Effects Division, Hanscom AFB, MA 01731.

M. Lockwood, Rutherford Appleton Laboratory, Chilton, Didcot, OX11 0QX, United Kingdom.

(Received December 29, 1992; revised November 19, 1993;

accepted September 9, 1993.) 